\title{
Hydraulic Transmission of Agricultural Machine Appropriate for Treating Extreme Steep Farmland Terrains
}

\author{
Martin KODRIČ, Stanislav PEHAN
}

\begin{abstract}
The paper presents the conception and design of the hydraulic transmission for agricultural machine appropriate for the treatment of extreme steep farmland. The small IC diesel engine powers a hydraulic pump that feeds the drive system as well as all working accessories. Hydraulic transmission systems perfectly satisfy the basic condition about the lowest weight but initially, they require totally new management. This paper outlines a simple but effective management system consisting of basic valves, electric sensors, and switches, which fits perfectly this specialized machine. The management enables the use of the potential energy for powering the accessories. When climbing up and downhill, the power is automatically distributed to the driving wheels or a winch, depending on the situation on the terrain. Significant working situations of the machine are predicted and analyzed. The appropriate function diagrams, hydraulic schemas and analytical calculations are presented. To raise the efficiency of the machine the close and the open hydraulic circuits are treated and analyzed. The machine is prototyped and partially tested. The results confirmed a big fuel saving of about 30 percent as predicted.
\end{abstract}

Keywords: agricultural machine; fuel saving; hydraulic transmission; steep terrain

\section{INTRODUCTION}

For treating steep terrain planted with permanent crops and inclined at angles greater than $60 \%$ normally a winch system is required [1]. The winch is usually mounted on the reef of the terrain which by a rope pulls the cart with the accessories upwards and then lets them go down, cycle after cycle. In this design, two different motors are needed. The first motor powers the winch system, the other one powers the accessories located on the cart. This machinery is limited in use because it works on steep terrain only. The even greater disadvantage of it is its inadequacy for using the potential energy. From the engineering point of view, this situation offers a nice challenge to design better machinery that would be able to use the potential energy and would not be so specific in use. The obvious challenge could be found in the analysis of the reasons for the extension of the use of the usual agricultural tractors.

For flat and steep terrains, which lie at angles less than $60 \%$, agriculture tractors with driving wheels or as a tracked vehicle are in use [2, 3] and [4]. The main reason for the limited use of the usual tractors at steep terrains is their too great weight. They would probably damage the undergrowth irreversibly. To avoid that, the farmers rather use a light cart with the accessories on it. The work with such a cart, which hangs from the rope, becomes in that way very time-consuming. The plant treatment becomes also incomparably expensive because of large fuel and time consumption. Uncertainty about choosing the proper machine is even greater in the case of mixed terrain. When the flat and very steep terrain segments are combined, the cart is substituted by the self-propelled machine with the winch firmly fixed on it [5]. The self-propelled machine is pulled and/or retained by the rope, which is anchored on the reef of the steep terrain. The IC engine indirectly drives the wheels or the winch. The machine is equipped with two accessories which can operate simultaneously, Fig. 1. When the machine moves uphill, both accessories should be switched off. All the IC engine power is used for climbing up by the machine. When the machine moves downhill the accessories are switched on. One accessory is powered by the IC engine, the other one can be powered by potential energy, for example [6].

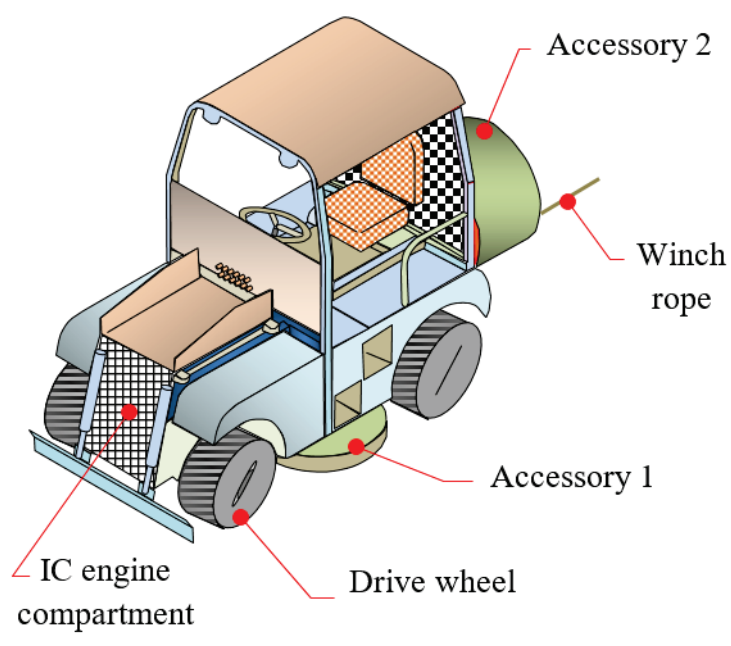

Figure 1 Virtual model of the new agricultural machine

The machine management system should enable the machine to run in different modes. In one mode, when the wheels are powered, the winch rotates with no resistance. In the second mode, when the winch is powered, then all wheels should rotate freely.

This paper is focused on the designing of such agricultural machine hydraulic transmission and the control of it. The main research attention is paid on raising the hydraulic efficiency by introducing the so-called open hydraulic circuit wherever that is sensible. The sense of using the modified hydraulic transmission is tested on the prototype machinery by measuring the total driving resistances. Introducing the open hydraulic circuits, controlled by the automatic system of sensors and the solenoid valves, results in reduced fuel consumption.

\section{HYDRAULIC TRANSMISSION DESIGN}

On the new agricultural machine three pumps are installed. Pump 1drives hydro motors on wheels or (and) winch, pumps 2 and 3 are driven by hydro motors on 
accessories. Pump 1 is an axial piston pump and works on a closed hydraulic cycle, pumps 2 and 3 are gear pumps and work on the open hydraulic cycle. The base motor of the agricultural machine is the small internal combustion diesel engine (IC engine), that drives the hydraulic pumps 1 and 2, Fig. 2. Pump 3 is driven indirectly by a winch, Fig. 4 The criterion for the determination of the IC engine power is the climbing abilities of the agricultural machine.

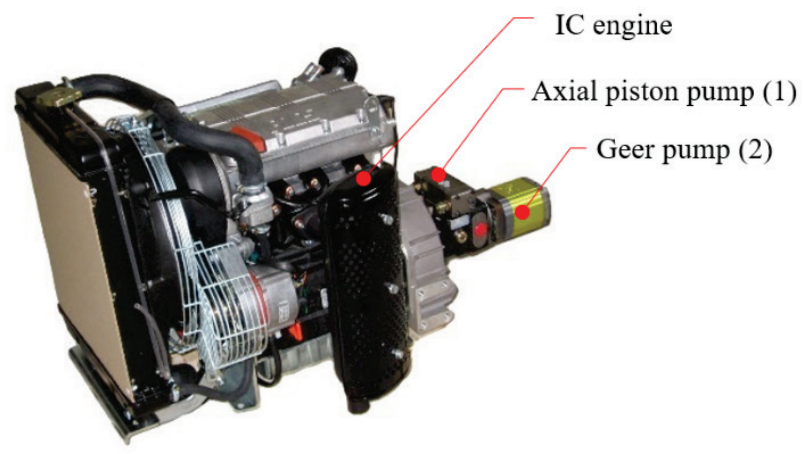

Figure 2 IC engine with pumps

The hydraulic power transmission for driving the machine consists of two main units. The first one is the wheel drive and the second one is the winch with the anchoring rope, Fig. 3. The winch and wheel drive can work separately or simultaneously. The hydraulic power transmission for driving the accessories consists of two power sources. The first one is the IC engine and the second one is the potential energy. When moving the agricultural machine upwards, all the engine power is consumed merely for this. When the agricultural machine is moving downhill or it is moving on a mostly flat field, the IC engine via hydraulics drives one accessory. When the agricultural machine is moving downhill in a steep area, the potential energy drives the second accessories. This potential energy is gained for free and it can be used as the primary energy source for operating.

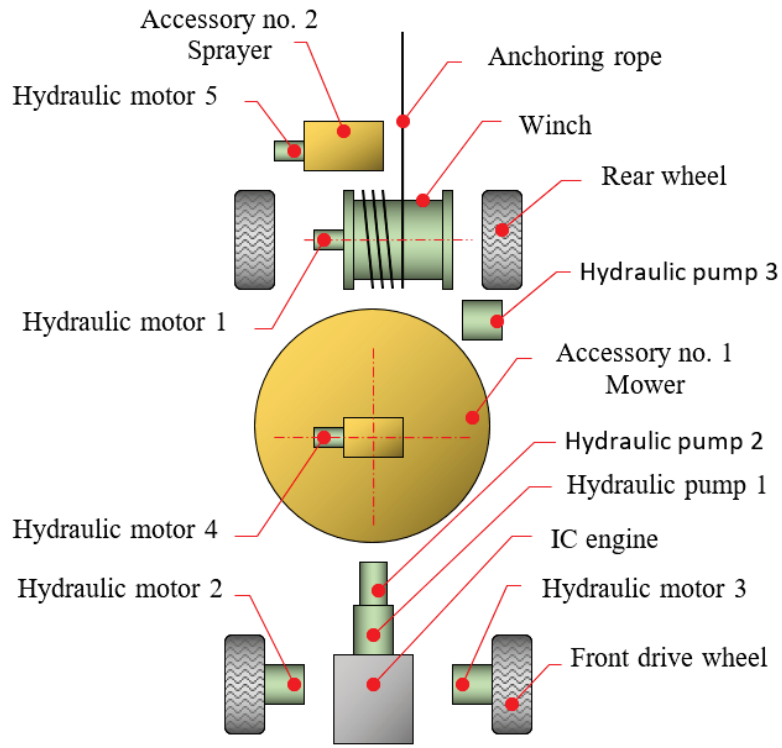

Figure 3 The layout of the main components of the agricultural machine

The potential energy is coming from the wheels and from the anchoring rope at the same time and it should be transformed into pertinent torque and rotational speed that is required from the accessories. This transformation can be done by hydraulic transmission [7, 8] and [9]. In case of using a mechanical gear, such problems could appear that cannot be overcome by already known systems.

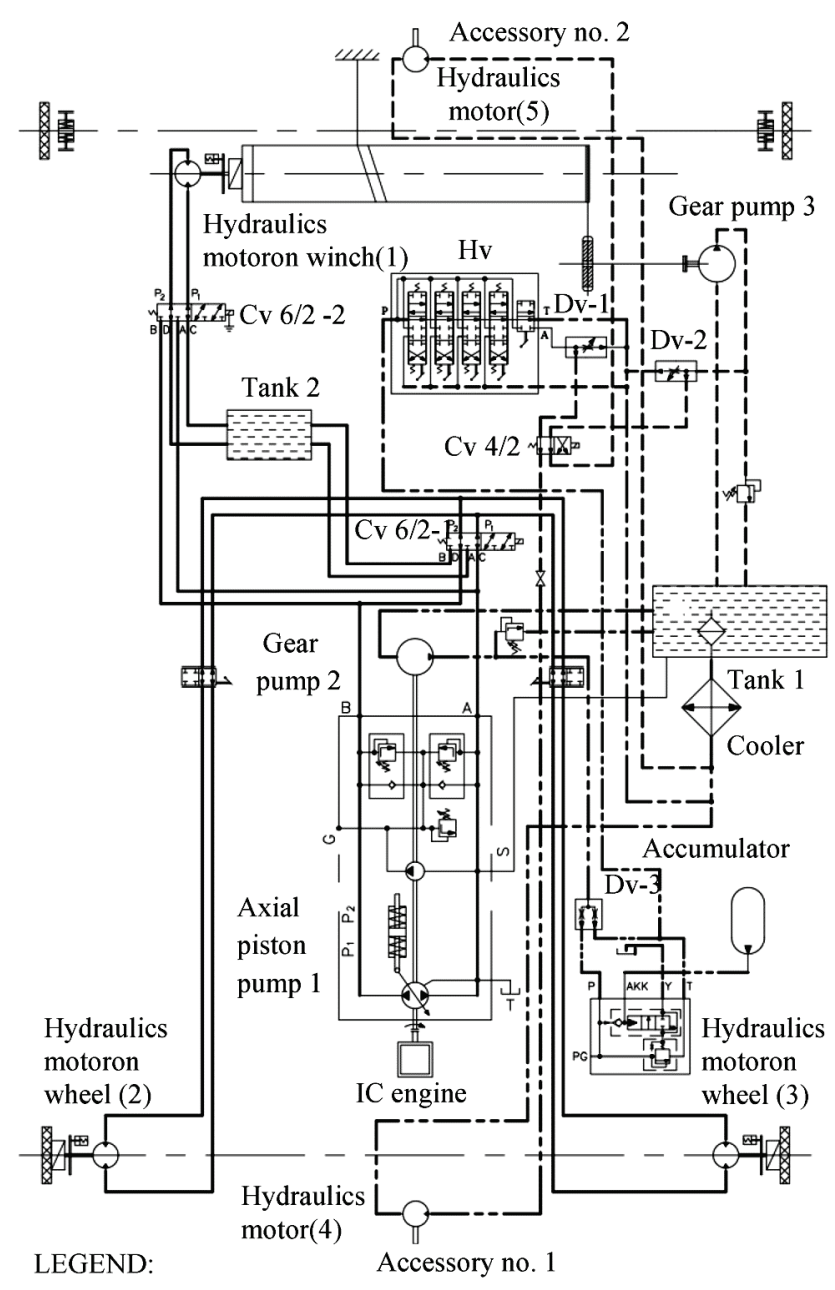

\begin{tabular}{ll}
$\longrightarrow$ & Drive machine \\
\hdashline--- & Drive accessory 2 \\
--- & Drive accessory 1
\end{tabular}

Figure 4 Diagram of hydraulic transmission of Power

Power transmission is shown in Fig. 4, where $\mathrm{Cv}$ is a control valve, $\mathrm{Dv}$ is a dividing valve and $\mathrm{Hv}$ is a hand valve. The continuous line shows power transmission for the machine drive. Axial piston pump 1 presses the oil via control valves $\mathrm{Cv} 6 / 2-1$ and $\mathrm{Cv} 6 / 2-2$ to the hydro motors on wheels and/or winch, then the oil comes back to the axial piston pump. For the machine drive, the IC engine is the power source. Control valves $\mathrm{Cv} 6 / 2-1$ and $\mathrm{Cv} 6 / 2-2$ enable one to switch off/on the wheel or winch drive. The agricultural machine can be equipped with serial accessories, as they are: spreader, side cutter, spring cutter, sprayer, excavator and many other standard accessories. The accessories can obtain the necessary power from the IC engine indirectly, or they can be powered with the potential energy obtained from the hydraulic system. Centre line shows power transmission for drive accessory 1, Fig. 4. Gear pump 2 presses oil via valves Dv-3, Hv, Dv1 and $\mathrm{Cv} 4 / 2$ to hydro motor 4 on accessory 1 , then oil goes back via the cooler into tank 1 . For accessory 1 drive, the IC engine is the power source. The hidden line shows the power transmission for drive accessory 2, Fig. 4. Gear 
pump 3 presses oil via valves Dv-2 and $\mathrm{Cv} 4 / 2$ to hydraulic motor 5 on accessory 2 , then oil goes back via the cooler to tank 1. The potential energy is the power source for drive accessory 2 . The potential energy can come from the tense winch rope, which powers the additional pump and that produces the pressure energy in the hydraulic system. The major advantage of the presented hydraulic system is its ability to combine the two energy sources and to transform their energy into proper input torque and rpm adequate for accessories. 4/2 control valve allows one to select the accessories. Oil is stored in two tanks, Fig. 4. The volume of tank 1 is 401 , the volume of tank 2 is 151 . Tank 1 is installed at the bottom of the machine to improve the stability of the machine. Tank 2 serves to relieve the system (pressure drop) and it is installed higher than the control valves $\mathrm{Cv}$ 6/2-1 and $\mathrm{Cv}$ 6/2-2. Tab. 1 shows oil pressure and the flow in different regimes in which the machine works.

Table 1 Oil pressure and flow

\begin{tabular}{|c|c|c|c|}
\hline & $\begin{array}{c}\text { Pump 1: } \\
\text { to run the } \\
\text { hydraulic motor } \\
\text { of winch and (or) } \\
\text { wheel }\end{array}$ & $\begin{array}{c}\text { Pump 2: } \\
\text { to run the } \\
\text { hydraulicmotor of } \\
\text { Accessory } 1\end{array}$ & $\begin{array}{c}\text { Pump 3: } \\
\text { to run the } \\
\text { hydraulic motor } \\
\text { of } \\
\text { Accessory } 2\end{array}$ \\
\hline $\begin{array}{l}\text { Machine } \\
\text { moving } \\
\text { uphill }\end{array}$ & $\begin{array}{l}\text { Pressure: } \\
\text { up to } 160 \text { bar } \\
\text { Flow: } \\
\text { up to } 641 / \mathrm{min}\end{array}$ & $\begin{array}{l}\text { The oil circulates. } \\
\text { Pressure: } \\
\text { up to } 20 \mathrm{bar} \\
\text { Flow: } \\
\text { up to } 401 / \mathrm{min}\end{array}$ & $\begin{array}{l}\text { Pump STOP. } \\
\text { Pressure: } 0 \text { bar } \\
\text { Flow: } 0 \text { 1/min }\end{array}$ \\
\hline $\begin{array}{l}\text { Machine } \\
\text { moving } \\
\text { downhill }\end{array}$ & $\begin{array}{c}\text { The oil circulates. } \\
\text { Pressure: } \\
\text { up to } 20 \text { bar } \\
\text { Flow: } \\
\text { up to } 641 / \mathrm{min}\end{array}$ & $\begin{array}{l}\text { Pressure: } \\
\text { up to } 160 \text { bar } \\
\text { Flow: } \\
\text { up to } 401 / \mathrm{min}\end{array}$ & $\begin{array}{l}\text { Pressure: } \\
\text { up to } 160 \text { bar } \\
\text { Flow: } \\
\text { up to } 401 / \mathrm{min}\end{array}$ \\
\hline
\end{tabular}

The hydraulic power transmission is designed in such a way that the oil heating is less than $60{ }^{\circ} \mathrm{C}$ [10] and the oil volume is relatively small. This allows cyclic operation of pump 1 and pumps 2 and 3. But anyway an oil cooler with a capacity of $80 \mathrm{l} / \mathrm{min}$ is installed on the machine Fig. 4. About $50 \%$ of working time pump 1 is loaded, the other $50 \%$ of working time pumps 2 and 3 are loaded. When the machine drives downhill, pumps 2 and 3 are at full load, pump 1 works with minimal pressure. In this case, each pump ( 2 and 3 ) gives $40 \mathrm{l} / \mathrm{min}$ oil with the pressure of 160 bar (total $80 \mathrm{l} / \mathrm{min}$ ). Oil circulates from pumps 1 and 2 to hydraulic motor 4 and 5 , via the cooler to tank 1 . The oil, which comes from an axial piston pump, circulates with minimal pressure via hydro motors on a wheel or winch and goes back to the axial piston pump. The part of oil which is isolated in the open hydraulic cycle circulates from tank 2 via hydraulics motor(s) on a wheel or winch and goes back to tank 2 where it is cooled. When the machine drives uphill, pump 1 is fully loaded and gives the flow of $64 \mathrm{l} / \mathrm{min}$ with the pressure of 160 bar. Pump 2 works with the minimal pressure of oil. The oil freely circulates from the pump and via the bypass pipe outside hydraulic motor via the cooler to tank 1. Pump 3 is stopped. For the new machine with hydraulic power transmission, it is important that it works with low pressure (about 160 bar). The operation of the machine with lower pressure causes less oil heating and lower energy losses [11], Eq. (1).

$$
p=p(v, \rho, T)
$$

where $p$ is the pressure of oil; $v$ is velosity of oil; $\rho$ is density of the oil and $T$ is temperature of the oil. The oil temperature affects the volume of the oil, Eq. (2).

$\Delta V=\alpha_{T} \cdot V_{0} \cdot \Delta T$

where $\Delta V$ is volume diference; $\alpha_{T}$ is the coefficient of stretching; $V_{0}$ is initial volume and $\Delta_{T}$ is temperature difference.

\section{CONTROL AND OPERATION OF THE MACHINE}

The control of the machine includes machine drive, accessory drive and potential energy conversion into pressure energy of oil. Because the machine works on terrains with different slopes it is possible to switch the individual drive branches on, off or circuit position. Tab. 2 presents examples when wheel or winch branches are on, off or in circuit position. The circuit position means that oil freely moves between branches. It uses an open hydraulic circuit. The machine control is maximally automated. The best results of the control are obtained by a combined electro-hydraulic steering system [12]. The electrical power source for an electric control system is the electrical accumulator. The oil, which is used for the hydraulic control system, comes from a small servo pump which is located inside the axial piston pump.

Table 2 On/off and circuit mode of wheel and winch drive

\begin{tabular}{|c|c|c|}
\hline $\begin{array}{c}\text { Terrain slope - driving } \\
\text { direction }\end{array}$ & $\begin{array}{c}\text { Wheel drive } \\
\text { branch status }\end{array}$ & $\begin{array}{c}\text { Winch drive } \\
\text { branch status }\end{array}$ \\
\hline up to $60 \%$ - forward, back & ON & OFF \\
\hline greater than $60 \%$ - up & ON/CIRCUIT & ON \\
\hline greater than $60 \%$ - down & ON/CIRCUIT & ON/CIRCUIT \\
\hline
\end{tabular}

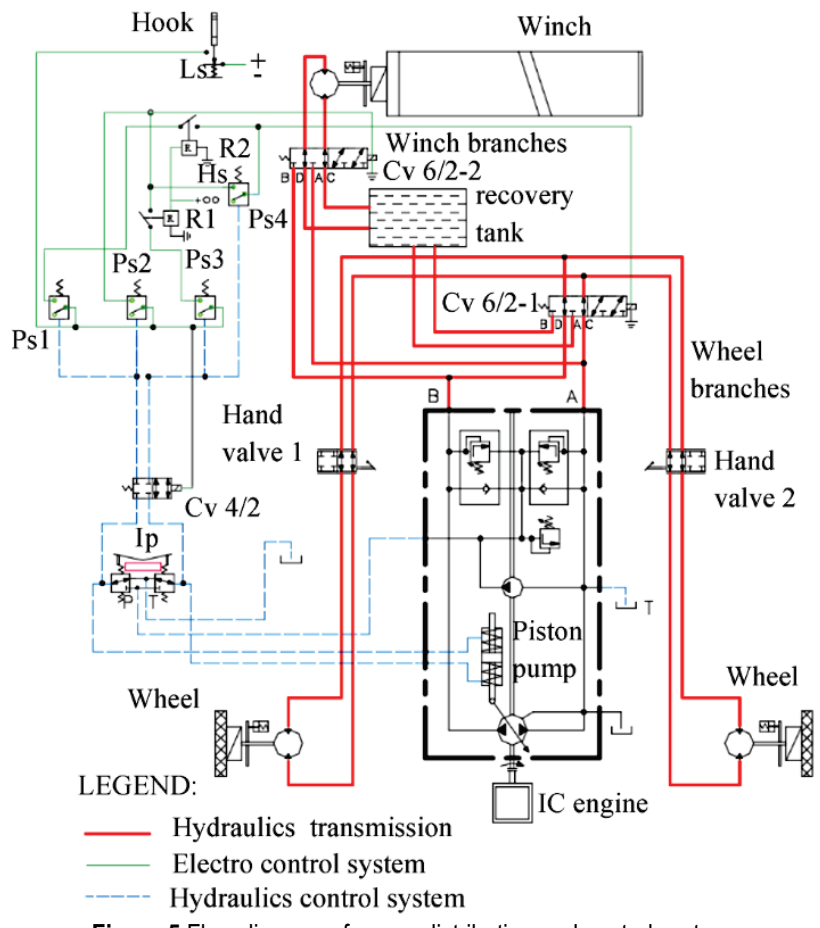

Figure 5 Flow diagram of power distribution and control system 


\subsection{Control of the Machine Drive}

The hydraulic transmission of the machine drive includes power transfer from the regulated piston pump over control valve $6 / 2-1$ and/or control valve $6 / 2-2$ to hydraulic motors on a wheel and/or winch branches. Then oil comes back to a pump - bold continuous (red) line in Fig. 5. The main control units are pressure switches Ps1, Ps2, Ps3 and Ps4, relays R1 and R2, Control valves Cv 6/2$1, \mathrm{Cv} 6 / 2-2, \mathrm{Cv} 4 / 2$, Inch pedal Ip and Limit switch Ls, Fig. 5. The thin continuous (green) line in Fig. 5 shows a function diagram of the electro-control system. The dash (blue) line in Fig. 5 shows a function diagram of the hydraulic control system. The working principle of the control system is as follows: when the machine moves on terrain with a gradient up to $60 \%$, the hook presses on the limit switch. The limit switch disconnects the electrical power supply from electro control valves and relays. In this example the winch branch is switched off, the wheel branches are switched on. When the machine moves on terrain with a gradient greater than $60 \%$, the hook is fastened to the anchor.

\begin{tabular}{|c|c|c|c|}
\hline $\begin{array}{c}\text { Slope } \\
\text { Drive } \\
\text { Drive situation }\end{array}$ & Control unit & Position & Activation \\
\hline $\begin{array}{l}\text { From flat to } 60 \% \\
\text { Wheel } \\
\text { Forward, backward }\end{array}$ & $\begin{array}{l}\text { Hook, Ls } \\
\text { Ip }\end{array}$ & $\begin{array}{c}\text { OFF } \\
\text { Forward, backward }\end{array}$ & $\begin{array}{l}\text { Manual } \\
\text { By foot }\end{array}$ \\
\hline $\begin{array}{l}\text { Greater than } 60 \% \\
\text { Wheel and winch } \\
\text { Up backward }\end{array}$ & $\begin{array}{l}\text { Hook, Ls } \\
\text { Ip } \\
\text { Cv } 4 / 2 \\
\text { Ps2 }\end{array}$ & $\begin{array}{c}\text { ON } \\
\text { Backward } \\
\text { ON } \\
\text { ON }\end{array}$ & $\begin{array}{l}\text { Manual } \\
\text { By foot } \\
\text { Automatic } \\
\text { Automatic }\end{array}$ \\
\hline $\begin{array}{l}\text { Greater than } 60 \% \\
\text { Winch } \\
\text { Up backward }\end{array}$ & $\begin{array}{c}\text { Hook, Ls } \\
\text { Ip } \\
\text { Cv 4/2 } \\
\text { Hs } \\
\text { Ps1 } \\
\text { Ps2 } \\
\text { R2 } \\
\text { Cv 6/2-1 }\end{array}$ & $\begin{array}{c}\text { ON } \\
\text { Backward } \\
\text { ON } \\
\text { ON } \\
\text { ON } \\
\text { ON } \\
\text { ON } \\
\text { OFF }\end{array}$ & $\begin{array}{c}\text { Manual } \\
\text { By foot } \\
\text { Automatic } \\
\text { Manual } \\
\text { Automatic } \\
\text { Automatic } \\
\text { Automatic } \\
\text { Automatic }\end{array}$ \\
\hline $\begin{array}{l}\text { Greater than } 60 \% \\
\text { Winch } \\
\text { Down forward }\end{array}$ & $\begin{array}{c}\text { Hook, Ls } \\
\text { Ip } \\
\text { Cv 4/2 } \\
\text { Hs } \\
\text { Ps3 } \\
\text { Ps4 } \\
\text { R1 } \\
\text { R2 } \\
\text { Cv 6/2-1 } \\
\text { Cv 6/2-2 }\end{array}$ & $\begin{array}{c}\text { ON } \\
\text { Forward } \\
\text { ON } \\
\text { ON } \\
\text { ON } \\
\text { ON } \\
\text { ON } \\
\text { ON } \\
\text { OFF } \\
\text { ON } \\
\end{array}$ & $\begin{array}{c}\text { Manual } \\
\text { By foot } \\
\text { Automatic } \\
\text { Manual } \\
\text { Automatic } \\
\text { Automatic } \\
\text { Automatic } \\
\text { Automatic } \\
\text { Automatic } \\
\text { Automatic }\end{array}$ \\
\hline $\begin{array}{l}\text { Greater than } 60 \% \\
\text { Wheel } \\
\text { Down forward }\end{array}$ & $\begin{array}{c}\text { Hook, Ls } \\
\text { Ip } \\
\text { Cv 4/2 } \\
\text { Hs } \\
\text { R } 1 \\
\text { R2 } \\
\text { Cv 6/2-1 } \\
\text { Cv 6/2-2 }\end{array}$ & $\begin{array}{c}\text { ON } \\
\text { Forward } \\
\text { ON } \\
\text { OFF } \\
\text { OFF } \\
\text { OFF } \\
\text { ON } \\
\text { OFF }\end{array}$ & $\begin{array}{c}\text { Manual } \\
\text { By foot } \\
\text { Automatic } \\
\text { Manual } \\
\text { Automatic } \\
\text { Automatic } \\
\text { Automatic } \\
\text { Automatic }\end{array}$ \\
\hline
\end{tabular}

The limit switch connects the electrical power supply with electrical control elements. The control valve $4 / 2$ moves in the open position. The inch pedal can be activated when the IC engine is running. If the inch pedal is pressed back, an oil pressure activates Ps1 and Ps2. The Ps2 enables power supply for control valve $6 / 2-2$. The valve is in on position. The winch drive is run. In this case, the machine would go uphill with wheel and winch drive. To switch off the wheel drive and to enable the oil circulating in a wheel branch, a hand switch must be turned to the on position. The electrical power supply connects R2 and moves the control valve $6 / 2-1$ to position off. In this case the machine will move uphill only by the winch drive. When the machine moves downhill on a steep terrain only, one branch must be switched on. Oil in the other branches must circulate. In this case, it is necessary to press on the inch pedal forward. The oil pressure activates a pressure switch Ps3 and Ps4. If the hand switch is in position on, the electrical power supply comes to $\mathrm{R} 1$ and $\mathrm{Cv} 6 / 2-2$. The valve goes into the position on. The machine downhill is with a winch drive. For driving downhill with wheel drive the hand switch must be in position off. This causes loss of electrical power supply for R1and R2. Both relays are open and control valve $6 / 2-2$ is moved in position off, control valve $6 / 2-1$ is moved in position on. Positions and activation mode of control units are presented in Tab. 3 .

The hook and hand switch are only activated by hand. The inch pedal is activated by foot. All other units are activated automatically. The position of the hook defines the area in which the machine is working. The machine drives on steep terrain with the incline up to $60 \%$, when the hook is located at the limit switch. The machine drives on steep terrain with an incline greater than $60 \%$, when the hook connects with the anchor. The hand switch is used for the switch on or off the wheel drive.

\subsection{Control of the Accessories Drive}

To convert the potential energy into pressure energy of the oil the gear pump is used, which is located on the winch, Fig. 4.

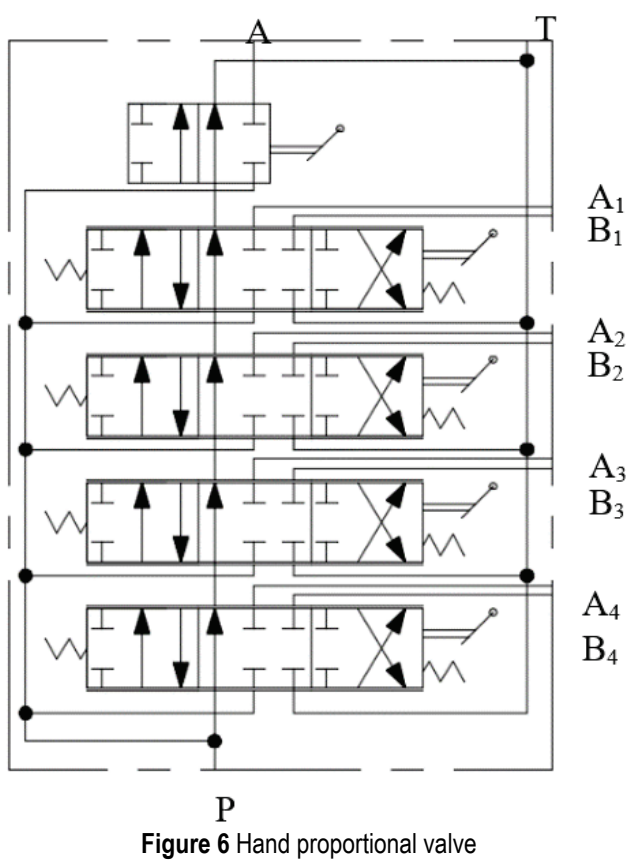

The second gear pump is directly connected to the IC engine. When the machine drives downhill it is possible simultaneously to use two rotary hydraulics motors and four linear hydraulics motors which run accessories.

The gear pump 2, which is connected directly to the IC engine, starts automatically with the IC engine. The oil flow depends on the rotational speed of the IC engine. The 
pump, which is located on the winch, starts when the machine starts to drive downhill. The oil flow depends on the drive speed of the machine. The four linear motors are controlled by hand proportional valve, Fig. 6. On the one side of a block of four proportional valves, it is located on/off valve, which enables oil flow to one rotary hydraulic motor. The control valve $4 / 2$ is used for changing supply between two accessories. The valve is controlled with a hand switch. To control the speed of accessories a divisible valve is used.

\subsection{Operation of the Machine}

The machine operator only takes care of managing basic functions such as the electric start of the IC motor, speed control of the IC motor, driving direction selection of machine, wheel drive on/off, switching on/off the accessories, controlling the speed of the accessories and steering the wheels. The physical prototype of the machine, which is manufacturing ready, is shown in Fig. 7.
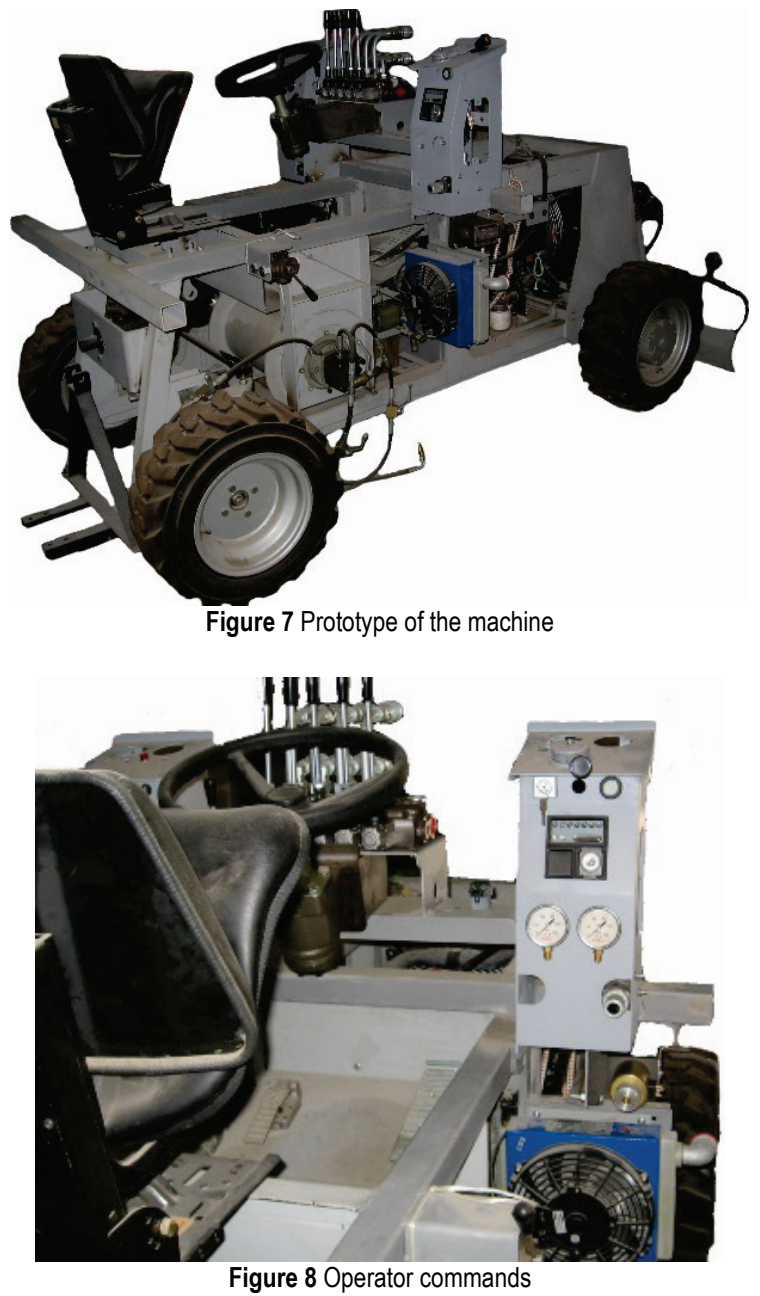

The operator commands are shown in Fig. 8. The machine operator activates the electric start of the drive motor with the key. He then manually sets the speed of the IC motor. With the inch pedal, he then selects the direction of the machine moving, the speed of the machine and the torque on the wheels or on the winch. Before the machine starts moving downhill, the machine operator can activate a hand valve for operating one accessory. The other accessories which use the potential energy are activated by the divisible valve.

When the machine is running on steep terrain, the operator activates or deactivates the wheel drive of the machine if it is necessary. If the operator deactivates the wheel drive when the machine moves uphill, the winch drive is still jet activated. If the operator deactivates the wheel drive when the machine moves downhill, the winch drive automatically starts. If the operator activates the wheel drive when the machine moves downhill, the winch drive is automatically deactivated. All other machine control functions follow automatically. The machine has built-in connections for installing remote control equipment.

\section{MACHINE PROTOTYPE TESTING}

The prototype of the machine was made and hydraulic properties were tested, Fig. 11. The main purpose of testing is to determine the difference in resistance between the closed and open hydraulic circuits. On the new machine with the hydraulic transmission of power, it is possible to switch off the winch or wheel drive.

To enable the rotation of the switched off hydraulic motor the free circuit of the hydraulic fluid should be enabled. The oil can be circulated in a closed hydraulic circuit, Fig. 9 or in an open hydraulic circuit, Fig. 10. In this case, the hydraulic motor, which is switched off, operates as a pump that pushes the flow inside the closed local circuit.

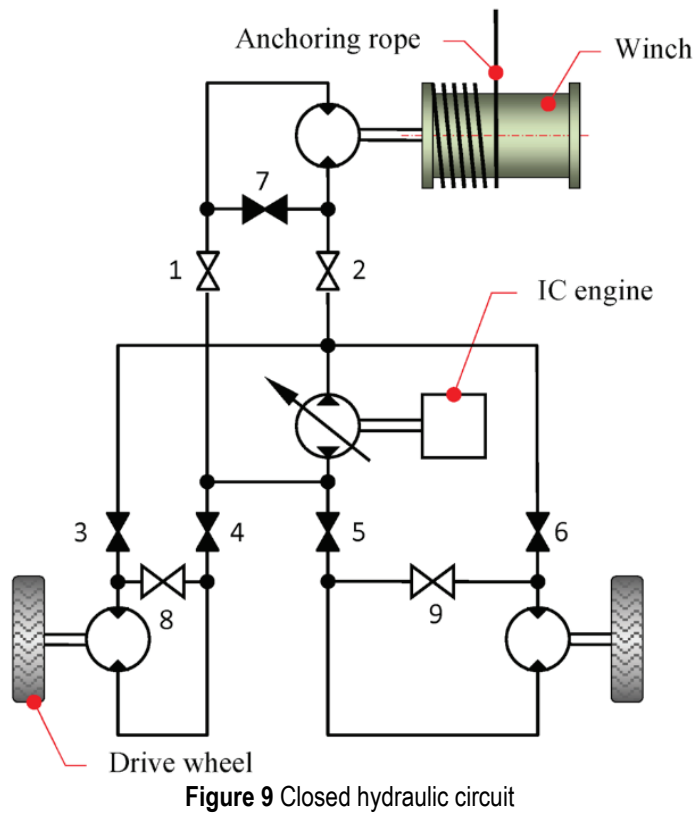

For example, at the operating the winch drive only, the valves 3, 4, 5, 6 and 7 are closed and the valves 1, 2, 8 and 9 are open, Fig. 9 . Also by the switched off circuit due to the previous operating conditions the high pressure in the piping still exists and causes harmful resistances, which leads to the power loss that heats the hydraulic system.

To overcome this disadvantage of the closed circuit the open circuit is introduced, Fig. 10. The most prominent component of the open hydraulic circuit is a recovery tank, that is functioning at atmospheric pressure. The inlet and outlet pipes of each hydraulic motor are connected with it. 
In case of operating the winch drive only, the valves 3,4 , 5, 6, 7 and 12 are closed and the valves $1,2,8,9,10$ and 11 are open, Fig. 10. Hydraulic fluid in both wheel branches can now freely circulate at the atmospheric condition and at negligible low resistance. Hydraulic fluid freely circulates from the reservoir through the hydraulic motor, which acts as a pump, and is returning back into the recovery tank with symbolic resistance only.

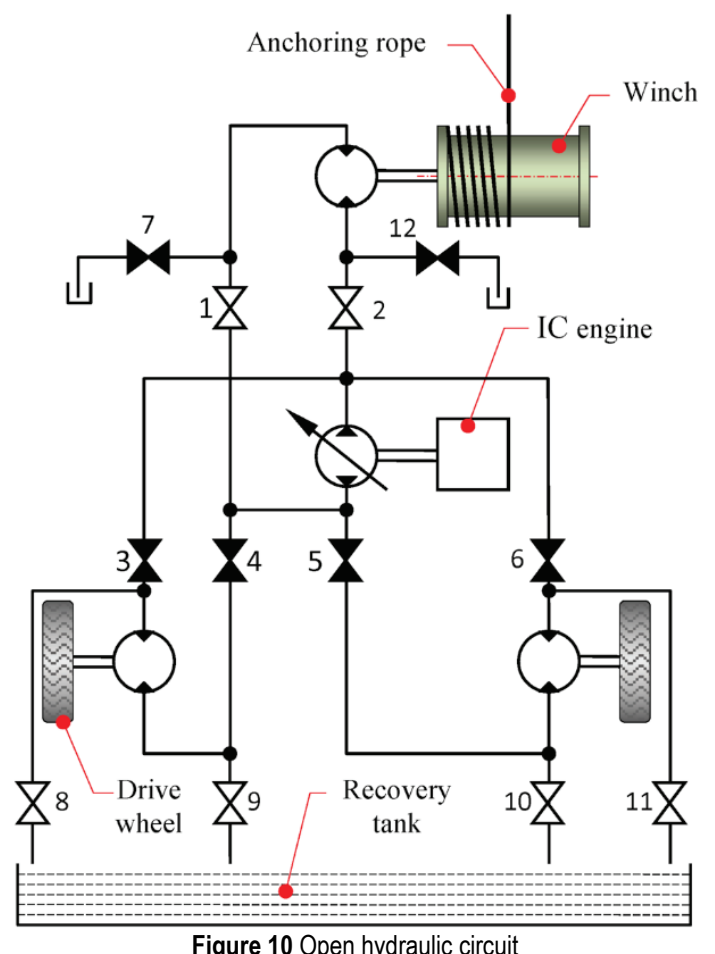

Figure 10 Open hydraulic circuit

Tab. 4 shows general data about pressure on the inlet and on the outlet side of the hydraulic motor, when the hydraulic motor rotates freely in the closed cycle and rotates freely in the open cycle.

Table 4 Pressures on the inlet and outlet side of the hydraulic motor

\begin{tabular}{|c|c|c|c|}
\hline & $\begin{array}{c}\text { Inlet side } \\
\text { pressure, } p_{1}\end{array}$ & $\begin{array}{c}\text { Outlet side } \\
\text { pressure, } p_{2}\end{array}$ & $\begin{array}{c}\text { Pressure in } \\
\text { system, } \Delta p\end{array}$ \\
\hline Closed circuit & $p_{1}<p_{2}$ & $p_{2}>p_{1}$ & $\Delta p>0$ \\
\hline Open circuit & 0 & 0 & 0 \\
\hline
\end{tabular}

In the event that the hydraulic motor drives the wheel or winch, the inlet pressure $p_{1}$ is bigger than zero, the outlet pressure $p_{2}$ is lower than $p_{1}$, and the difference of pressures is bigger than zero. This situation is characteristic for normal power flow from an IC engine to wheels or a winch, Eqs. (3) and (4).

$$
\begin{aligned}
& P_{\mathrm{hm}}=\frac{\Delta p_{\mathrm{hm}} \cdot Q_{\mathrm{hm}} \cdot \eta_{\mathrm{hm}}}{600} \\
& \Delta p_{\mathrm{hm}}=p_{1}-p_{2}
\end{aligned}
$$

Here $P_{\mathrm{hm}}$ is the power of the hydraulic motor; $\Delta p_{\mathrm{hm}}$ is the pressure difference between the inlet and the outlet sides of the hydraulic motor; $\eta_{\mathrm{hm}}$ is the efficiency of the hydraulic motor. In the case of the opposite power flow, the hydraulic motors on wheels, or hydraulic motor on the winch, can become or be transformed into actual pumps. In the closed hydraulic circuit, the inlet pressure, $p_{1}$, is lower than the outlet pressure, $p_{2}$. Consequently, the pressure in the system, $\Delta p$, is greater than zero. This pressure causes power losses into hydraulic components that rotate. In the case of the open hydraulic circuit, all the actual pressures are zero. The only power losses due to the component rotations are those caused by fluid flow, these can be neglected.

From this analysis, it can be concluded that there is the evident advantage of using the open hydraulic circuit which is expressed in higher efficiency of the agricultural machine.

The influence of the pressure in the hydraulic circuit for the winch was tested. The test rig consisted of a hand hydraulic pump, which was connected by piping and appropriate hand valves on the real winch with the hydraulic motor OMS 100 and gearbox with the speed reduction of 6.2 . The diameter of the winch drum was $273 \mathrm{~mm}$.

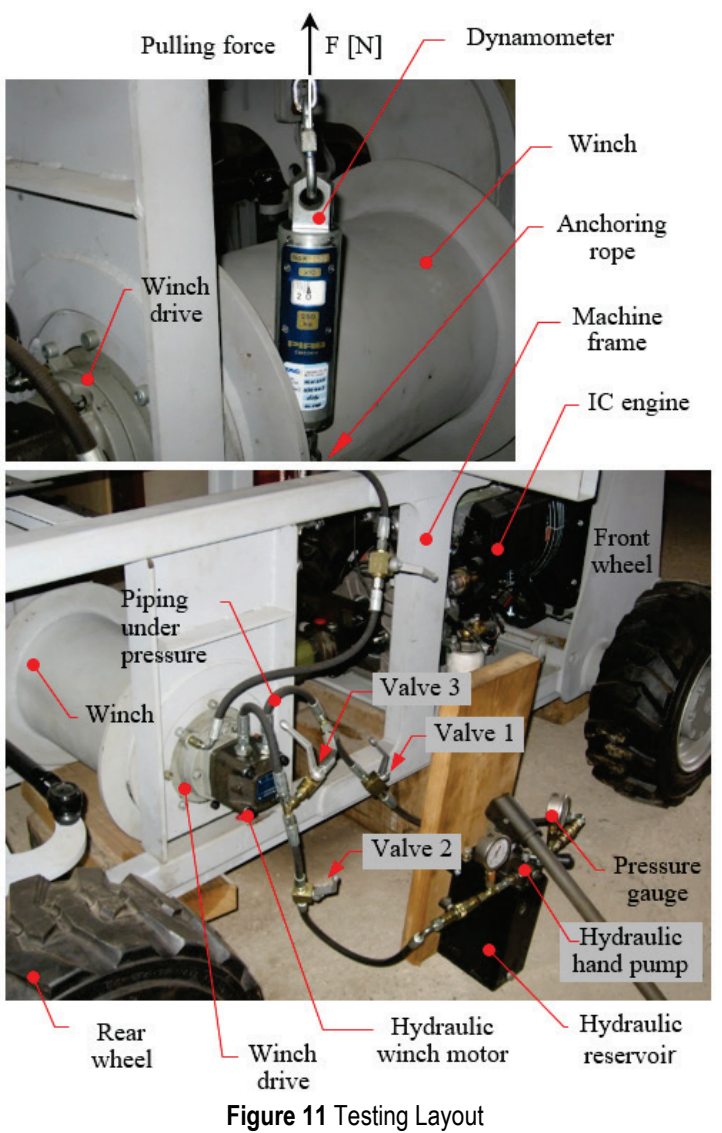

The rope diameter was $10 \mathrm{~mm}$. The first test performed was the resistance of the closed hydraulic circuit. The winch was driven by a hydraulic hand pump. The valves 1 and 2 were opened, the valve 3 was closed. The valves 1 and 2 were suddenly closed, the valve 3 opened, and then the tangential force on the winch drum was measured. Testing was performed at several pressures which were gradually increased up to 60 bars. With the same equipment, an open hydraulic circuit was tested. In this case, the valves 1 and 2 were opened, the valve 3 was closed. By the hand pump, the pressure in the system was again raised to the normal level that was required to drive the winch. Immediately after stopping the hand pump the 
pressure in the pipelines dropped to the atmospheric level. The tangential force in the pulling rope was measured.

\section{$5 \quad$ RESULTS AND DISCUSSION}

It is important that the agricultural machine is manufactured in accordance with the presented premise and that it works excellently. The solution of hydraulic power transmission proved to be appropriate. The hydraulic power transmission includes the machine drive and the accessory drive. The machine drive includes a winch and/or a wheel drive which can work simultaneously or separately. When the wheel or the winch drive is switched off, the hydraulic motor works as a pump in an open hydraulic cycle. Both the closed and open hydraulics cycles were tested on the prototype of the machine. The results of testing and advantage of the open hydraulic circuit are shown in Fig. 12. Here, the measurement of hydraulic resistance on the winch drive is presented but the situation is completely identical with respect to all other hydraulic motors. The results of the test have shown that the open hydraulic cycle is significantly more favorable for the free circulation of the hydraulic oil. This confirms the correct construction choice of hydraulic power transmission.

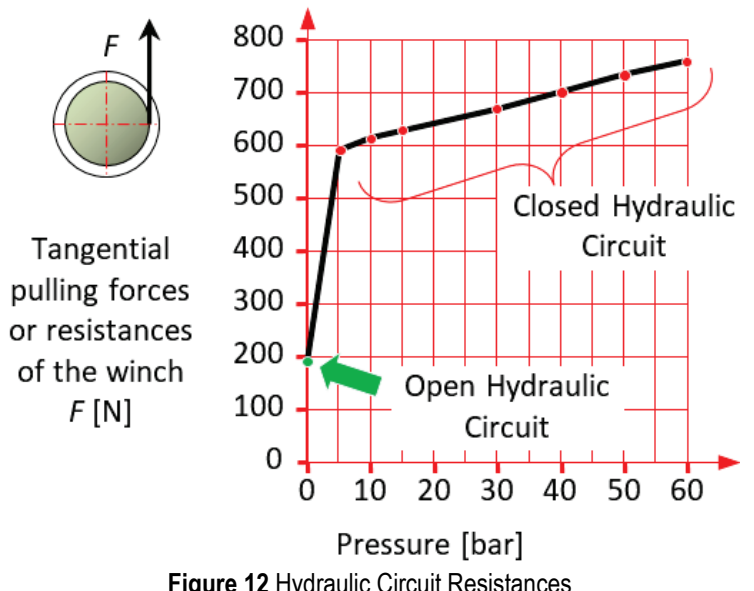

The innovation of the machine is the two power sources: the IC engine and potential energy. The potential energy is used for one accessory drive when the machine moves downhill. The potential energy is converted into the pressure energy of oil. When the machine moves uphill, the wheels or the winch drive are at full load. When the machine moves downhill, the accessory drive is at full load. This principle of machine work is appropriate for oil cooling. The machine has an electric hydraulic control system. A lot of functions work automatically so the operation of the machine is very simple. It is possible to install on the machine the equipment for remote control. The small mass of the hydraulic power system and the small power of the IC engine are typical for the machine. This article presents only the principles of operation of hydraulic systems.

\section{CONCLUSION}

In this paper, it is presented the hydraulic power transmission on an agricultural machine, that is appropriate for treating extreme steep farmland terrains. The new technical solutions for the use of potential energy are shown. The prototype of the machine has been made. For the determination of the resistance, the open and closed hydraulic cycles are tested. The main purpose was to find a technical solution and to create a machine that would be significantly better than the competitive ones. The initial assumption about the advantage of open hydraulic is fully confirmed by the theories and the experiments.

\section{REFERENCES}

[1] Bohme, A. (2003). Umweltgerechte Technik den Steillagenweinbau. KTBL, Darmstadt.

[2] Bernik, R. (2004). Techniques in Agriculture. Biotechnical Faculty, Department of Agronomy.

[3] Vidoni, R., Bietresato, M., Gasparetto, A., \& Mazetto, F. (2015). Evaluation and stability comparison of different vehicle configurations for robotic agricultural operations on side slopes. Biosystems Engineering, 129, 197-211. https://doi.org/10.1016/j.biosystemseng.2014.10.003

[4] Hrastar, K. (2014). Tractor Catalogue. Ljubljana: published by ČZD Kmečki glas: Handbook.

[5] Kodrič, M. (2016). Development of a hybrid machine for working on sloping terrain. Doctoral Thesis, University of Maribor.

[6] Katrašnik, T., Trenc, F., \& Oprešnik, S. (2007). Study of the Energy-Conversion Efficiency of Hybrid Powertrains. Strojniški vestnik - Journal of Mechanical Engineering, 53 (10), 667-682.

[7] Akers, A., Gassman, M., \& Smith, R. (2006). Hydraulic power system analysis. Iowa State University, USA. https://doi.org/10.1201/9781420014587

[8] Flašker, J. \& Pehan, S. (2005). Power Transmissions. Textbook Maribor: Faculty of Mechanical Engineering.

[9] Kodrič, M., Flašker, J., \& Pehan, S. (2017). Efficiency Improvement of Agricultural Winch Machines. Journal of Mechanical Engineering 63, 171-180. https://doi.org/10.5545/sv-jme.2016.3968

[10] Lovrec, D. \& Kambič M. (2007). Hidravlične tekočine in njihova nega. University of Maribor.

[11] Savić, V., Knežević, D., Lovrec, D., Jocanović, M., \& Karanović, V. (2009). Determination of Pressure Losses in Hydraulic Pipeline Systems by Considering Temperature and Pressure. Faculty of Mechanical Engineering, University of Maribor, Slovenia.

[12] Chengqiang, Y., Qun, S., Yian, W., Chengqiang, L., \& Jie, G. (2017). Development of Electrohydraulic Steering Control System for Tractor Automatic Navigation. Journal of Electrical and Computer Engineering, Article ID 5617253 .

Contact information:

Martin KODRIČ, PhD

(Corresponding author)

Nuclear Power Plant Krško,

Vrbina 12, 8270 Krško, Slovenia

E-mail: martin.kodric@nek.s

Stanislav PEHAN, PhD, Associate Professor

University of Maribor, Faculty of Mechanical Engineering

Smetanova ulica 17, 2000 Maribor, Slovenia

E-mail: stanislav.pehan@um.s 